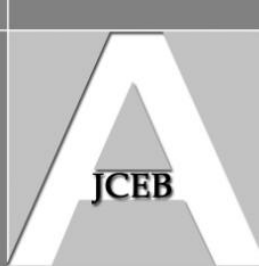

\title{
An Alignment Model for the Research Higher Degree Supervision Process Using Repertory Grids - Reflections on Application in Practice in Built Environment Research
}

\author{
Guillermo Aranda-Mena (RMIT University, Australia ) \\ Rod Gameson (University of Salford, United Kingdom)
}

\begin{abstract}
From $P h D$-doing to $P h D$-done is not as from $A$ to $B$. This research aims to improve the understanding of the complex relationship between doctoral research and the supervisory process. The research model developed utilises repertory-grids and discussion is presented in relation to the nature of factors contributing to successful completions. The paper is argumentative in nature and provides insights to a complex process which is largely untested. A supervisory model previously presented by the authors (Aranda-Mena \& Gameson, 2004) is tested in two areas: (1) the research process and (2) personality factors. The research increases common understanding of what it takes to complete a $\mathrm{PhD}$, and the supervisory challenges in such a long process. It is concluded that supervision is a key factor in completing a $\mathrm{PhD}$, and in developing the intellectual, analytical and research skills expected of $\mathrm{PhD}$ graduates. The authors call for more research, both theoretical and, in particular, empirical, in this important area.
\end{abstract}

Keywords: Built environment, Doctorate, Research supervision

\section{Introduction}

An awareness and understanding by both student and supervisor of the research process that lies ahead is critical to the success of any research higher degree studies (Boud and Lee, 2009), given an increase in the types (e.g. traditional PhD, Professional Doctorate, DSc, DBA) and modes (e.g. full-time, part-time, online, split-site) of higher degree studies now available (Park, 2005; University of Salford, No Date). For example, Denicolo et al (2010) report a 71\% increase, from 2000-01 to 2005-06, in students studying for professional doctorates in the United Kingdom (UK). A key driver for facilitating successful and timely completions is the input of such data to national research assessment exercises such as: the UK's 'Research Excellence Framework [REF]' (HEFCE, 2011), and the Australian 'Excellence in Research for Australia [ERA]' (Commonwealth of Australia, 2010).

Previous research has identified the issue of research supervision as being a critical factor in PhD completions (Baird, 1995; Barnes \& Austin, 2009; HEFCE, 2011; Wichmann-Hansen et al, 2012). A major Australian report on PhD supervision, conducted at the Australian National University [ANU], (Cullen et al, 1994, p.108), concluded that, "...the identification of effective supervisory practice was best accomplished not through simple aggregation of existing best practice, but rather through the deconstruction of supervisory practice and through the identification of those aspects of supervisory practice which would most benefit from strengthening, elaboration and change." The report also identifies three main issues requiring attention:

- "Supervision should be conceptualised to encompass a broad view of PhD education which includes more than one-to-one interaction of a student and a supervisor;

- Programs for staff and students to improve practice can and should be designed to contextualise the generic process of supervision with attention to disciplinary and usual human variation, and, 
- There is a need to go beyond individual supervisory interactions and restructure practice to ensure that responsibility for quality is shared and co-ordinated." (Cullen et al, 1994, p.108-109).

The objective of this research is to critically review theoretical issues pertaining to the research supervisory process and the student - supervisor relationship, and identify key factors. A principal conclusion of Haksever \& Manisali's (2000) research of construction management and engineering students, was that the development of a framework to, 'promote dialogue', between students and supervisors would contribute to improved outcomes, which could include: improved contributions to knowledge and more highly developed student research skills. Such a framework, in terms of the proposal of a supervisor-student alignment model, is also described and discussed.

\section{Doing a PhD}

There has been an upward trend in the number of students commencing PhD studies in the UK. Data published by HEFCE (2011) shows a significant increase of $62 \%$ in students commencing PhDs from 14,045 in 1996/97 to 22,790 in 2009/10. HEFCE (2011) also reports an increase of $71 \%$ in PhD starters in the 'engineering / technology / building / architecture' subject area over the same period.

A key factor to consider is how PhD 'starters' translate into PhD 'completions'. HEFCE (2005, p. 4) state that, "by 2000-01, after five years, 57 per cent of PhD students who began their studies on a full-time course, and 19 per cent starting on a part-time course had completed. By 2002-03, after seven years, the completion rates were 71 per cent and 34 per cent for full-time and part-time starters respectively." This data shows that, after seven years of study, $29 \%$ of full-time students, and $66 \%$ of part-time students had not completed their studies. A major Australian study by Sinclair (2004, p.v) states that, "Sixty-four per cent of PhD candidates supervised over the 1990-97 period were conferred with the award of Doctor of Philosophy." This result is similar to another Australian study conducted by Martin et al (2001) which estimated that only $65 \%$ of doctoral candidates completed their degrees. A HEFCE (2012) report presents projected rates of qualification of students on postgraduate research degrees. For students who commenced their studies in 2009/10, 67.6\% are predicted to complete within 7 years, and $75.6 \%$ within 25 years. Therefore, it is predicted that $32.4 \%$ of these students will not complete their studies by $2016 / 17$.

A survey by Harman (2003) of Australian research-intensive universities discovered low student satisfaction levels due to poor quality of supervision. Specific issues identified by students included: quality and effectiveness of supervision, interpersonal skills of the supervisor and help provided in designing their projects. Harman (2003) also identified the issue of an expansion in PhD enrolments in Australia since the early 1990's, suggesting that universities had not kept pace with the needs of a growing body of research students, leading to increasing levels of student dissatisfaction. A survey of UK PhD students, reported by Haksever \& Manisali (2000), found that $30 \%$ of the cases cited, relating to non-completion of construction management and engineering students, were specifically due to problems with supervision; in particular 'direct research-related help', defined as, "...critical analysis of work, help with methodological problems, precise direction and help with the management of the project" (Haksever \& Manisali, 2000, p.21).

In summary therefore, the data presented in this section identifies a problem with level of 'completions' of $\mathrm{PhD}$ research, with a key contributory factor being the quality of research supervision. 


\section{The Research Process}

There are many books that purport to give guidance on research processes and methods, both in general terms (i.e. Howard and Sharp, 1983; Phillips and Pugh, 1987; Jankowicz, 1995) and, more recently, built environment related texts (i.e. Fellows and Liu, 1997; Runeson and Skitmore, 1999; Knight and Ruddock, 2008; Farrell, 2011). Such books are now increasingly supplemented by resources available to postgraduate researchers online (i.e. Vitae, 2011).

The stages of research could be regarded as sequential, starting with theory development and ending with conclusions. This could be considered as a 'traditional' model of research, aligning with Hughes's (1994) construction management contextualised view of a PhD process of, "...consisting of three trimesters, the first to define and contextualize the problem [the theory], the second to do the field work [the test] and the third to write the thesis [concluding]." These three components of research could be more appropriately represented as three points on a 'circle of research' where, given different research approaches and/or methodological positions, the starting point of the research process may not always be the 'theory' component (Marshall and Rossman, 1989). One example of an alternative would be the 'grounded theory' approach where, as Strauss and Corbin (1990: p23) state, "One does not begin with the theory, then prove it. Rather, one begins with an area of study and what is relevant to that area is allowed to emerge." Therefore new theory may emerge from a "test and conclude' exercise (Hunter and Kelly, 2008).

For the purpose of this paper the authors, whilst acknowledging that other methodological propositions exist, will present and discuss a 'traditional' research model of: building theory, testing theory and concluding.

\section{Building Theory}

There is a Chinese proverb, attributed to Lao-tzu, which says that, "A journey of a thousand miles begins with a single step." The first research 'step' involves an initial review of the underpinning theories which might have a relation to the questions under scrutiny. The theory of the research process, as a starting point, involves the selection of a topic and a research area. With some initial ideas in mind this first research 'step' should be a comprehensive literature search and critical review. In the past this step could prove to be difficult in terms of access to information being readily available. The growth in information technology (i.e. online journals, web-based articles and reports) has led to a proliferation in information available to researchers, requiring well-developed skills in information searching; particularly during this first step of the research to ensure that recent and relevant literature is discovered (Neuman, 1997). Students no longer have to wait 3 to 6 months for inter-library loans, or print extracts from borrowed PhDs from microfilm. Journal publishers often make papers available online before they are published in hard copy. With the internet being the main domain of information for students there is a potential risk of being overwhelmed by information, and coming across erroneous or misleading information.

Jankowicz (1995, p.26-28) proposes that researchers should ask themselves a number of questions when selecting and evaluating a research topic: Does it interest you? How much do you know about it already? How difficult is it likely to be? These three questions would be hard to answer without the assistance of a mentor or supervisor because of factors such as: the inexperience / capability of the student, and not utilising the experience of the supervisor (Barnes \& Austin, 2009). Hughes (1994) suggests that the first task for construction management students, in consultation with their supervisors, is to agree a detailed specification for the research, and goes on to cite Kane $(1985$, p.15) who contends that, "The most difficult hurdle to overcome in doing research is not in learning the techniques or doing the actual work or even writing the report. The biggest obstacle, surprisingly, lies in figuring out what you want to know."

Aranda-Mena, G and Gameson, R (2012) 'An alignment model for the research higher degree supervision process using repertory grids - reflections on application in practice in built environment research', Australasian Journal of Construction Economics and Building, 12 (3) 66-81 
Numerous authors have put forward suggestions as to how to focus research at this first 'step' of the process. Jankowicz (1995, p.34) suggests, "working up and narrowing down..." a topic by moving from an 'area' (i.e. construction management), to a 'field' (i.e. legal issues) to an 'aspect' (i.e. dispute resolution). Kane (1985) states that a 'research statement' should be produced, Howard \& Sharp (1983) propose a 'topic analysis', Leedy (1985) tenders the need for a 'problem statement' and Black (1993) contends the need for clear 'research questions and hypotheses'. Often an outcome of this step will be a 'research/thesis proposal' which, "...justifies and describes the proposed study." (Griffith \& Watson, 2008, p.185).

\section{Testing Theory}

Having clearly defined a research scope and developed a research direction the next 'step' is to define a satisfying research question, aim, objectives and, if appropriate, hypotheses. Given the wide range of types of research projects conducted in the field of construction management numerous different research methodologies, ranging from the natural to social sciences, may be utilised (Dainty, 2008). If the research involves the collection of empirical data the selection of appropriate valid, reliable and objective methodologies needs to be addressed (Black, 1993; Cresswell \& Miller, 1997). Perry (1998) draws a distinction between 'explanatory' research, which is quantitative (i.e. considering what the precise relationship between variables is), and can be considered, according to Mostyn (1985, p.116), to be, "...to determine what, where, when, and how many, rather than why.", and 'exploratory" research, which is of a qualitative nature (i.e. looking at what variables are involved).

A key consideration at this 'test' stage is to ensure that any research is conducted in an ethical manner. This is of particular importance when primary, non-publicly available data, such as questionnaires and interviews, are being conducted and/or where any data collection methods may impact upon humans. Therefore ethical approval procedures must be followed (University of Salford, 2010b; RMIT, 2011a). When considering this step in the research process at postgraduate level, it can be seen as another 'check-point' allowing further discussion between student and supervisor, and providing an indicator of the student's progress so far. Most Universities now have, as a minimum, a requirement for periodic assessment / review of a student's progress (i.e. RMIT, 2007; University of Salford, 2010a), notwithstanding the importance of regular student - supervisor meetings throughout the whole PhD process.

\section{Concluding}

The final, and critical, step in the research process is to reach an outcome in the form of conclusions. This involves comparing "theory" with "test" to determine if the research aim and objectives have been achieved, and, if the research has hypotheses, if they are proven, or not. Black (1993, p.175) provides a list of, "...common sources of misleading conclusions...", which includes: ignoring data which is contrary to the research hypothesis; conclusions extended to a larger population than the one investigated and conclusions beyond the stated research boundaries (i.e. aim and objectives).

This is also the end of the 'writing-up' of the research where it is critical that students clearly communicate what they have done in the research. Hughes (1994), commenting on PhDs in construction management, states that, for many students, the most daunting task is writingup their work. A logical structure and presentation of the research is essential, 'telling the story' to the reader, using typographically and grammatically correct conventions (see good and bad examples in: Truss, 2003). The Australian model of examination, based upon reading and assessment of the thesis by two or three external examiners, with no oral examination which is also common in other parts of the world such as Europe (Tinkler \& Jackson, 2000), places significant importance upon how students write up their research. The defence of the thesis which takes place in an oral examination needs to, where no oral occurs, be made very explicitly in words, and other visual media, on paper.

Aranda-Mena, G and Gameson, R (2012) 'An alignment model for the research higher degree supervision process using repertory grids - reflections on application in practice in built environment research', Australasian Journal of Construction Economics and Building, 12 (3) 66-81 


\section{PhD supervision as a Non-Linear Process}

Traditionally, both the literature and University printed guidance on the research process provides prescriptive guidance (University of Salford, 2010a; RMIT, 2011b). However, there are a limited number of sources that acknowledge the complex process of thesis development in higher degrees. The more typical literature, including Universities' own guides, often prove to be rigid and highly prescriptive about supervisor, supervisee and the thesis or object of study (Lawson, 2000). For example, Phillips \& Pugh (1987) suggest steps and sequential timetables. However, in reality, the situation often proves to be somewhat different. The process of doing a $\mathrm{PhD}$ is hardly one that goes from $a$ to $b$ to $c$. According to Grant (2003) the process is iterative, complex and unstable and, for the same reasons, it would seem sensible to develop more prescriptive approaches towards supervision. Figure 1 illustrates a model of the complexity and non-linearity in the supervision process. This model was first proposed by Grant (2003) and provides a potentially powerful tool to explicitly externalise the situation. Figure 1 also shows direct and indirect links in the 'supervisorstudent-thesis' relationship. The relationship between supervisor and student adjoins a third element of 'knowledge' which in the figure is represented by the thesis. Grant (2003) states that the relationship between these three elements is in constant change. Such an arrangement is affected through power relationships that work through actions; these actions have an effect upon the elements and highlight more subtle difficulties dealing with personality, cultural and power differences (Lee, 2007; 2008). Power relations can be a consequence of aspects of institutional position and can also vary across disciplines, institutions and nations (Hofstede, 1986).

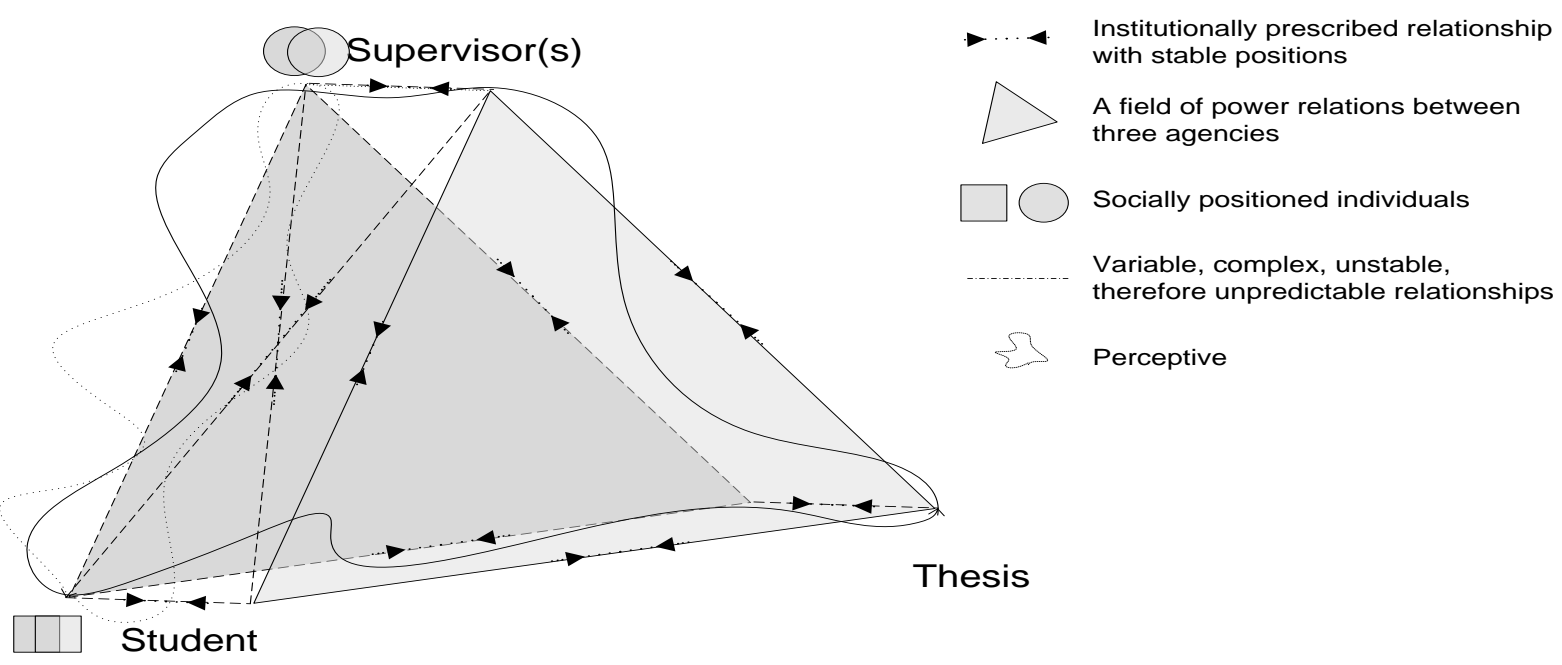

Figure 1 Student-supervisor multilayer relationship (Based on Grant, 2003)

Even if bright as undergraduates, neophyte higher degree researchers need to develop their skills further when conducting higher degree research. They can often be insecure, inexperienced, and demand close supervision. They may see the thesis as a culturally prescribed artefact and it may take some time before a student can comprehend the implications of doing postgraduate research (Johnson et al, 2000). Gurr (2001) suggests that the role of supervising would typically involve feedback, time, money, networks, and recognition to the student by an established authority in academia. Hughes (1997) disagrees with this and argues that the supervisor does not necessarily need to be an expert in all areas/fields and that the researcher should also seek support from within the department, the university and the wider research community. Whitelock et al (2008) suggest that 
promoting creativity in $\mathrm{PhD}$ supervision is important, but tensions and dilemmas within the student-supervisor relationship need to be resolved.

The dimensions of supervisory styles summarised in Table 1 were originally developed by Cullen et al (1994) to pinpoint the styles across individuals and academic disciplines. For instance, supervisors from computing, economics, physics and engineering disciplines tend to provide a closer style than those from arts, history or sociology. This relates to Hughes's (1994) discussion on styles in supervision in built environment research. He argues that building and built environment research should seek the support of core disciplines such as economics, law, cybernetics, psychology amongst others. If building-related research is to grow and be beneficial to industry and the wider scientific community, it must establish itself as a 'field of application'. If this is the case, it could exacerbate the complexities to apply standard codes of practice because areas of research supervision could span across many fields.

\begin{tabular}{|l|l|l|}
\hline Style: & Close & Hands off \\
\hline Meetings: & Regular, frequent & Irregular \\
\hline Project: & Collaborative & Individual \\
\hline Relation to supervisor's research: & Closely related & Unrelated \\
\hline Joint Publication: & The norm & Uncommon \\
\hline Mentorship: & The norm & Rare \\
\hline
\end{tabular}

Table 1 Supervisory styles (Cullen et al, 1994)

In the traditional sense, the supervisor-student relationship has been described by FAUSA (1979, p.21) as, "...the most important channel of intellectual inheritance between one generation and the next.", with good supervision being central to thesis completion (Lawson, 2000). On the other hand it is generally expected that research students should develop their own ideas and test their own hypotheses - and not that of their supervisors (Harman, 2003). A graduate from a higher degree by research (especially in PhDs) is expected to be academically competent and independent. Achieving this is, arguably, the most challenging test in the supervision process (Haksever \& Manisali, 2000).

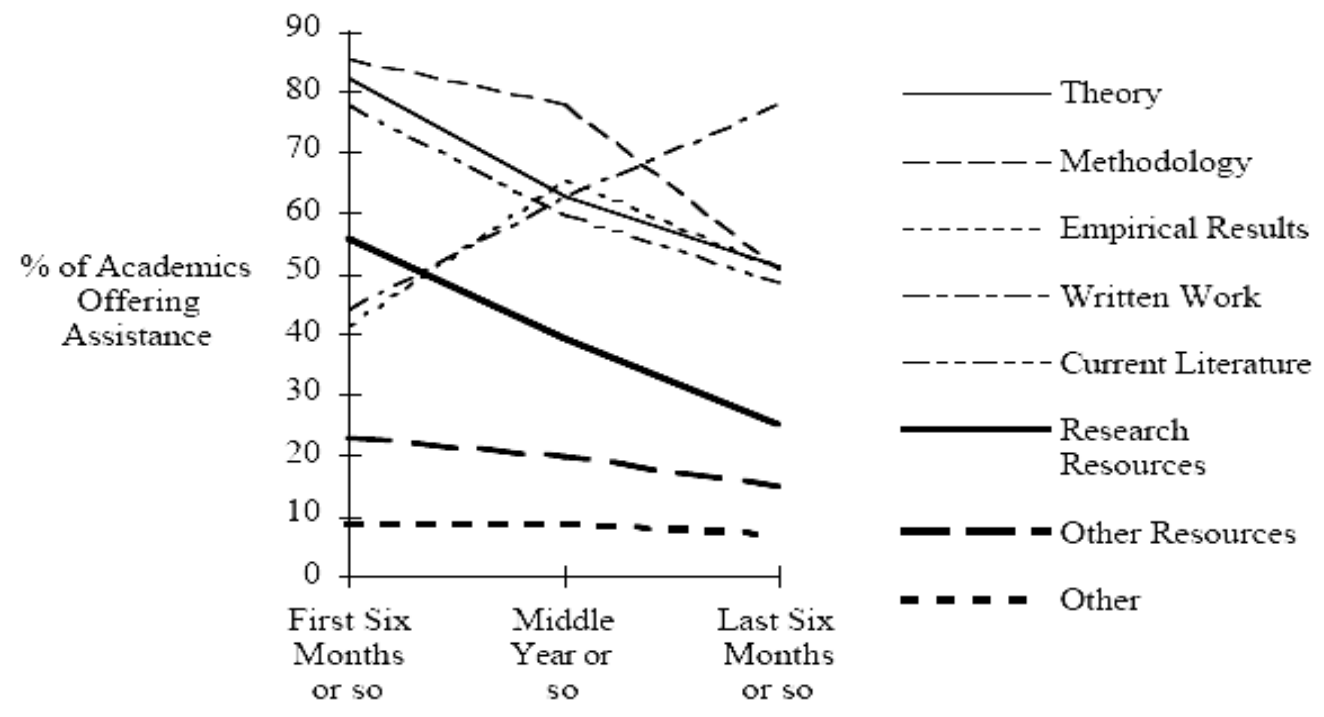

Figure 2 Supervisory assistance in research phases (Cullen et al, 1994, p.91)

Aranda-Mena, G and Gameson, R (2012) 'An alignment model for the research higher degree supervision process using repertory grids - reflections on application in practice in built environment research', Australasian Journal of Construction Economics and Building, 12 (3) 66-81 
Figure 2 presents the supervision process in terms of skills and expectations. Supervisees typically demand supervisory expertise in most of these areas (e.g. theory, methodology, writing skills, etc.). In reality it is very unlikely that a single supervisor possesses all of these skills. This often applies in social science related research where students are expected to develop critical thinking not just validating findings but defending their more philosophical standings such as ontological and epistemological positions (Heath, 2002).

\section{Aligning the Players}

This section introduces a model which, whilst being relatively simple, provides explicit value for academic supervision across the wide range of disciplines. The model seeks to raise awareness of the norms, expectations and standards within their discipline and be able to assess their own plans and actions to ensure compliance with them (Gurr, 2001). The aim is ultimately about teaching students to be their own supervisors (Phillips \& Pugh, 1987).

Gurr's (2001) model operates to promote a 'plan-act-review' learning cycle. In the increasingly common arrangement where associate supervisors or supervisory panels are involved, additional parties can be invited to join subsequent discussions. Figure 3 illustrates a dynamic alignment model which could be used in dialogue between a student and a supervisor to establish a shared understanding through reflection. The model is aimed at facilitating the production of a successful PhD thesis. A flexible approach is required on the part of the supervisor, an approach that should be informed by open discussion with the student (Vilkinas, 2002). This may then lead to establishing an appropriate supervisory style. Anderson (1988) developed a model comprising of the following four styles of supervision:

- "Direct active: Characterised by initiating, criticising, telling and directing;

- Indirect active: Characterised by asking for opinions and suggestions, accepting and expanding supervisee's ideas, or asking for explanations and justifications of supervisee's statements;

- Indirect passive: Characterised by listening and waiting for supervisees to process ideas and problem solving, and

- Passive: Characterised by having no input and not responding to supervisee's input." (Gurr, 2001, p.86).

Other emerging and increasingly popular modes of higher degrees by research include the Professional Doctorate (Chynoweth, 2006) and the embedded practice PhD. Examples of both of these modes, in the built environment, are currently delivered at RMIT University Schools of Architecture, Business Graduate Studies and School of Property, Construction and Project Management (RMIT, No Date). The University of Salford also delivers a Professional Doctorate where, "...candidates are encouraged to generate explicit academic knowledge from their wealth of existing tacit professional knowledge." (University of Salford, 2009). For these modes of doctoral studies the student-supervisor relationship takes on a different challenge (Walker, 2008).

In these cases the candidate is normally someone already established in industry and may have a supervisory committee of practitioners and academics. The candidates are request to report and present to the academic institution with progress reviews and presentations. Most of the time this would be done face-to-face but there are cases where such reviews may be conducted 'virtually' via video and/or teleconference. A particular challenge here is the lack of face-to-face contact time. There have been a number of successful completions, with outcomes including conference and journal paper publications; for example Bourne (2005) and Holzer (2009). Therefore, there is a need to find and use different and more innovative techniques to facilitate the student-supervisor relationship such as wiki-webs and social media, especially when geographic collocation is not possible. 


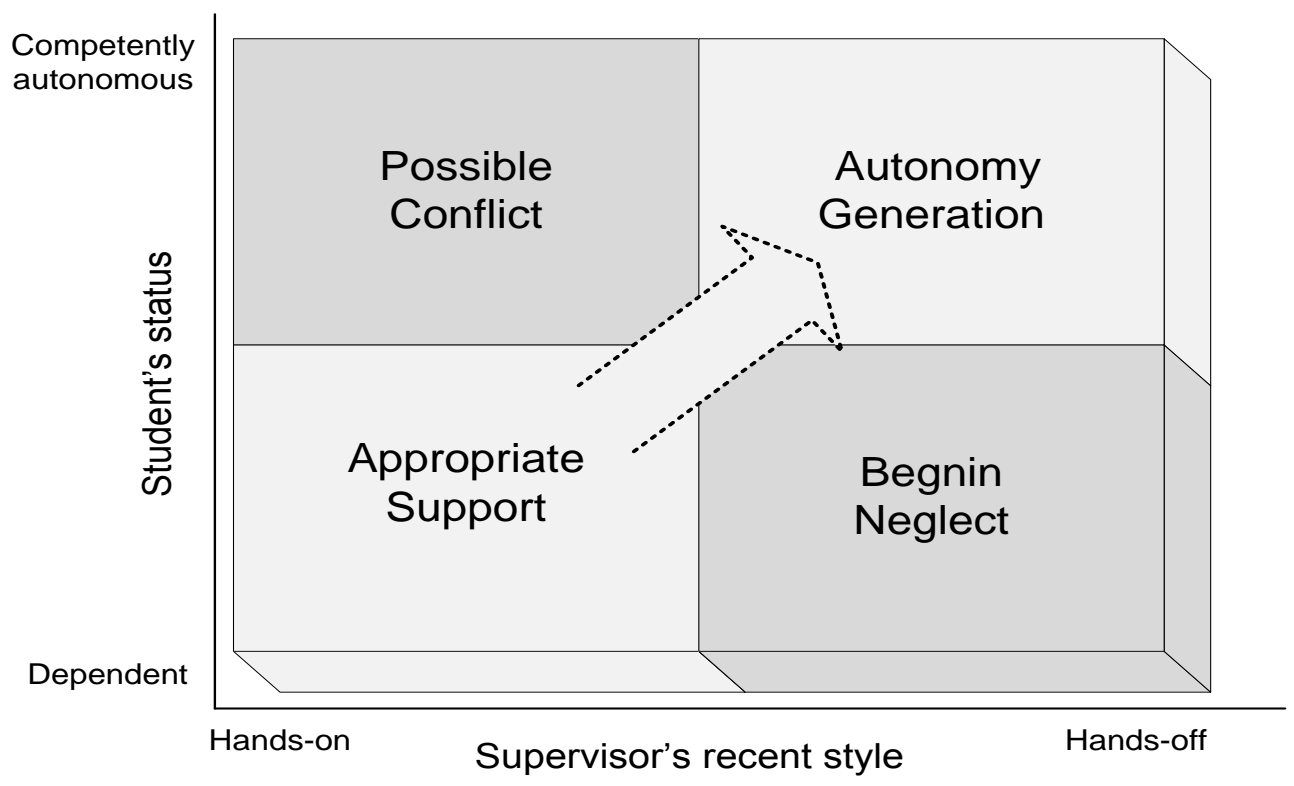

Figure 3 Dynamic alignment model (Gurr, 2001, p.87)

The research to date has not identified any existing, detailed models which could be used to capture perceptions of both students and supervisors during the PhD's life-cycle. BradburyJones (2007) presented a systematic approach for exploring subjectivity during doctoral studies, but only from a student's perspective. Therefore this research now proposes using the 'Repertory Grid' method to develop a model (Denicolo \& Pope, 2001). The repertory grid technique is based upon the principles of 'personal construct psychology' (Kelly, 1955). The use of an alignment model in conjunction with repertory grids provides a means of judging the degree of, and framework for working towards, effective supervision.

\section{Mapping-out the Process}

A comprehensive explanation of the personal construct theory and technique is beyond the scope of this paper. However, further information concerning the use and implementation of the technique can be found in Aranda \& Finch (2003). A repertory grid technique (RGT) is proposed to facilitate the implementation of Gurr's (2001) model. Denicolo \& Pope (2001) identify the value of repertory grids to explicitly indicate thinking in the supervision process, and to track and record perceptual and emotive changes, often a tacit phenomenon. RGT is therefore used to facilitate conversation, unearth insights and provide focus in the supervisory relationship.

Repertory Grid Technique (RGT) systems are traditionally developed through triad elicitation (e.g. Denicolo \& Pope, 2001). This means that a respondent or interviewee is asked to find similarities and differences of three elements at a time. Those similarities and differences become what are known as a,' bipolar construct system'. A series of bipolar constructs outline 'attributes' to a concept. In the context of this research such a concept would be 'supervision'. The numerical or hierarchical grading of such construct systems follows a similar procedure to that of the Likert scales (Allport, 1935) or Osgood's (1954) semantic differential. Ratings are assigned to a bi-polar construct system; this would facilitate a relational structure between elements and construct polarity (ie. quality - quantity).

\section{Mapping out: Repertory-Grids}

The following repertory grids were originally discussed in 2004 (Aranda-Mena \& Gameson, 2004) in relation to the perception and changes during the student-supervisor relationship. The repertory grid shown in figure 4 illustrates a focused construct system and its 
relationship and gap analysis as to what is perceived as effective supervision by both, the supervisor and the student. The grids provide a mechanism for further discussion, reflection and development of a new model.

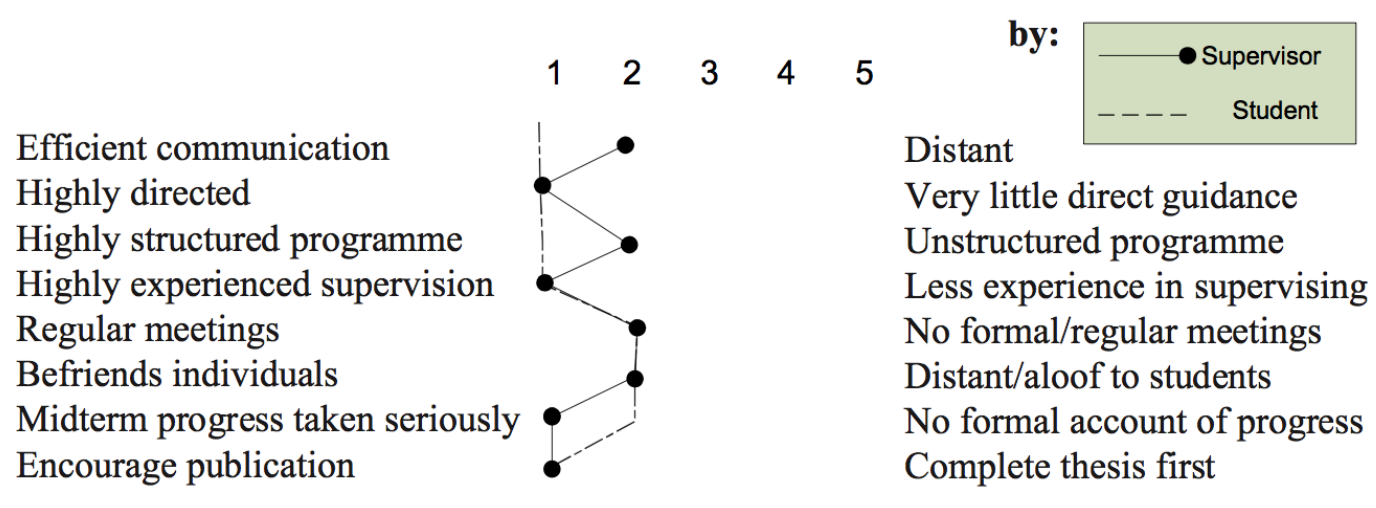

Appropriate Support

Autonomy Generation

Figure 4 Initial rating (i.e. topic definition)

At this initial stage, the student perceives appropriate support and the supervisor also considers that the supervisee needs it. However, according to Gurr (2001) close support should only take place at an initial stage - otherwise there is a high chance for this causing conflict (i.e. see Figure 3). At this initial stage the student is more receptive and the supervisor is rather paternalistic. The grid technique is for continuous use by both the supervisor and the student and is to provide a means for discussion over differences and expectations so as to monitor changes over time. The grid provides insight into what the student and the supervisor perceive to be 'effective supervision'.

\section{Perceived as effective}

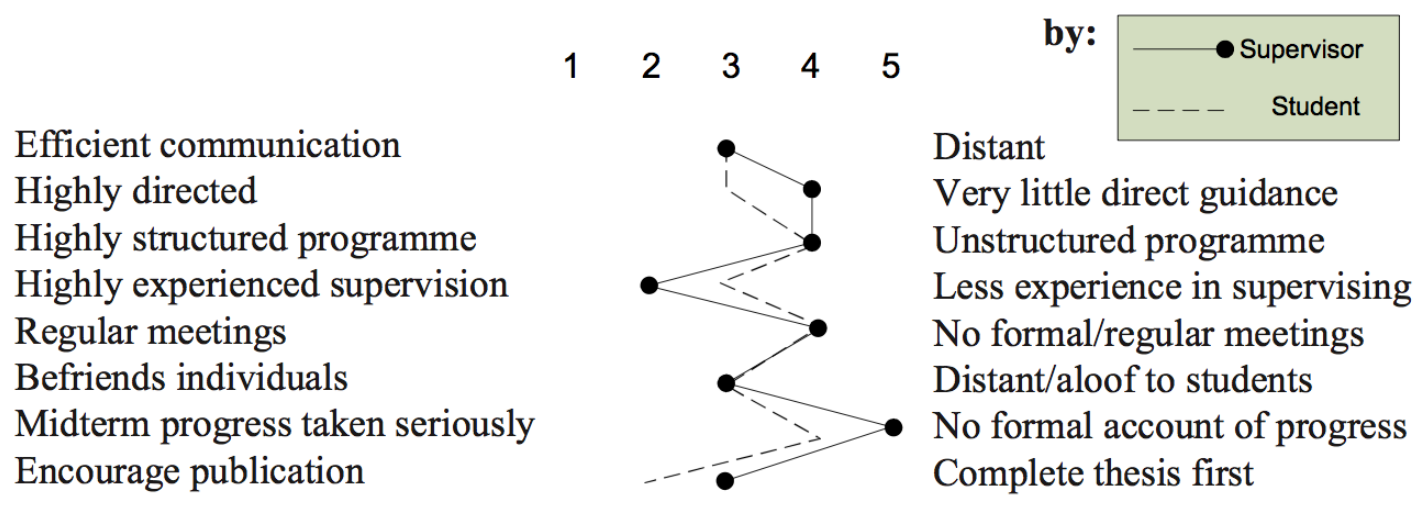

Appropriate Support

Autonomy Generation

Figure 5 Progress rating (i.e. theory development)

The repertory grid shown in figure 5 reveals how the student now perceives an appropriate supervisory style as the research develops. Certainly they are experiencing a more demanding stage with less direct guidance; the distance between the two has increased. At this stage the student has started building confidence and is more in tune with the situation.

The grid in figure 6 illustrates how the supervisor has moved towards a 'hands-off' style, which he or she perceives to be the effective one at this stage. The student has some anxieties but with the assistance of the grids, they can both discuss the current situation.

Aranda-Mena, G and Gameson, R (2012) 'An alignment model for the research higher degree supervision process using repertory grids - reflections on application in practice in built environment research', Australasian Journal of Construction Economics and Building, 12 (3) 66-81 
The supervisor may make it clear that it is time for the student to take 'authorship' of their work from this point onwards, which is expected in higher degrees. The student feels somehow neglected; however, it has been important to be aware of such expectations of the supervisor. Note that new bipolar constructs can emerge at any point.

\author{
Efficient communication \\ Highly directed \\ Highly structured programme \\ Highly experienced supervision \\ Regular meetings \\ Befriends individuals \\ Midterm progress taken seriously \\ Encourage publication
}

\section{Perceived as effective}

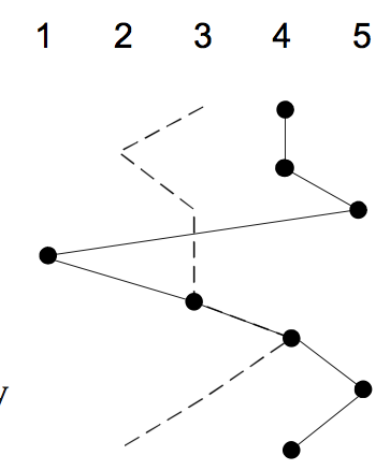

Distant

by:

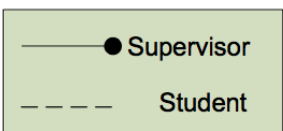

Very little direct guidance

Unstructured programme

Less experience in supervising

No formal/regular meetings

Distant/aloof to students

No formal account of progress

Complete thesis first

\section{Figure 6 Further progress rating (i.e. data analysis / testing)}

A breakthrough arises at this stage, as the student realises that he or she need to embrace or take control and direction of their project. The supervisor is still there but the relationship is somehow unstructured and there is no formal account of progress. The student frequently falls into procrastination and shifts attention to other activities such as tutoring and community work.

Figure 7 illustrates the situation towards thesis completion where the relationship seems to have improved. The student has overcome anxiety and insecurity and keeps better progress records by taking full control over the project. Although more confident, the student is always experiencing anxiety but this might remain until after the final examination.

$\begin{array}{lllllll} & & \text { Perceived as effective } \\ \text { Efficient communication } & & & \text { - Supervisor } \\ \text { Highly directed } & & & \end{array}$

\section{Appropriate Support}

\section{Autonomy Generation}

\section{Figure 7 Rating towards completion (concluding)}

The four grids above have been used to illustrate the personal perceptions of the supervisory process from both a student and a supervisor perspective. The vertical lines indicate 'perceived as effective' as seen/reflected by each party. The profile line of a cosupervisor could have been introduced here. It is contended that a co-supervisor could act as a bridge across the current existing supervisory gap. Arguably co-supervisors can only be effective if fully engaged in the process from the outset of the research.

Aranda-Mena, G and Gameson, R (2012) 'An alignment model for the research higher degree supervision process using repertory grids - reflections on application in practice in built environment research', Australasian Journal of Construction Economics and Building, 12 (3) 66-81 


\section{Mapping out: Cluster Analysis}

Having reflected upon the original model, developed in 2004, (Aranda-Mena \& Gameson, 2004), and conducted further research to identify relevant literature published since then, such as Gatfield's (2005) study of PhD supervisory styles, a more complex repertory grid has been developed to provide further insights into research supervision encompassing a range of modes such as single and multiple supervisors.

The model, as shown in figure 8 , is a repertory grid comprising of elements, relating to supervision, and bi-polar constructs.

The 'Elements' (i.e. supervision/supervisory support) are:
A) Single supervisor
B) Two supervisors
C) One industry and one academic supervisor
D) School academic board
E) School PhD students
F) Ghost supervisor
G) Two academic and one industry
$\mathrm{H})$ On-line interest groups such as CNBR

Emerging 'constructs' (i.e. attributes to supervision/supervisory support) after triads have been self-administered by the authors. Emerging constructs by comparing and contrasting elements form $\mathrm{A}$ to $\mathrm{H}$ are as follow:

1.- Relationship: [Left construct] Formal_-[Right construct] Informal

2.- Communication: [L]Argumentative-[R]Discussions

3.- Expertise: [L]Specialised-[R]Generic

4.- Engagement: [L]No ownership over the project-[R]Process Driven

5.- Vision: [L]Here and now-[R]Long term vision

6.- Opinion: [L]Valued-[R]Not Valued

7.- Proximity: [L]Physical/Psychological Closeness-[R]Remote

8.- Line of communication: [L]Three way relationship-[R]Unidirectional

9.- Line of communication: [L]Unidirectional one-to-one - [R]One-to-many

10.- Line of communication: [L]Unidirectional strong - [R]Unidirectional fragile/tenuous

11.- Line of communication: [L]Sessional triangle - [R]Sessional unidirectional

The resulting above Figure 8 indicates the relationship between supervision/supervisory support in a cross tabulated grid with attributes on the left and right columns indicating a relationship across all attributes with all elements (i.e. 8 elements from $A$ to $H$ ) and 11 bipolar constructs (22 individual tags either at the left (1) or right (5) sides of the grid). The shading indicates if a particular element is likely to relate to a Left to Right construct. For instance, Element $A$, Single Supervisor, is associated with the following constructs: 7R, 8R, $5 \mathrm{R}, 4 \mathrm{R}, 10 \mathrm{~L}, 1 \mathrm{~L}, 3 \mathrm{~L}, 2 \mathrm{~L}, 9 \mathrm{~L}, 11 \mathrm{R}$ and $6 \mathrm{R}$. The shadings also form clusters indicating similarities between elements and constructs. Such similarities are also indicated with the tree-shaped dendritic diagrams. The above grid indicates that supervision support as $\mathrm{G}, \mathrm{B}$ and $C$ (i.e. different modes of the supervisor and the co-supervisor) is seen as an effective supervisory mode. The contrasting situation is indicated by the proximity of $A$ with $F$ suggesting that the single supervisor is performing as a nowhere to be seen ghost supervisor!

The nodal points in the dendritic diagrams at the top and right-hand side of the grid indicate the proximity of elements or constructs on both the X-axis and the Y-axis. For instance, constructs 4 and 10 are the closest matching at 80 , whereas construct 5 (Vision) is the single most isolated construct with a match of 50 with any other construct. Constructs 7 (Proximity) and 8 (Line of communication) are isolated with the rest of all other constructs

Aranda-Mena, G and Gameson, R (2012) 'An alignment model for the research higher degree supervision process using repertory grids - reflections on application in practice in built environment research', Australasian Journal of Construction Economics and Building, 12 (3) 66-81 
matching at 30. Constructs 4 (Engagement) and 10 (Line of communication) are also closely aligned with a matching factor of 80 .

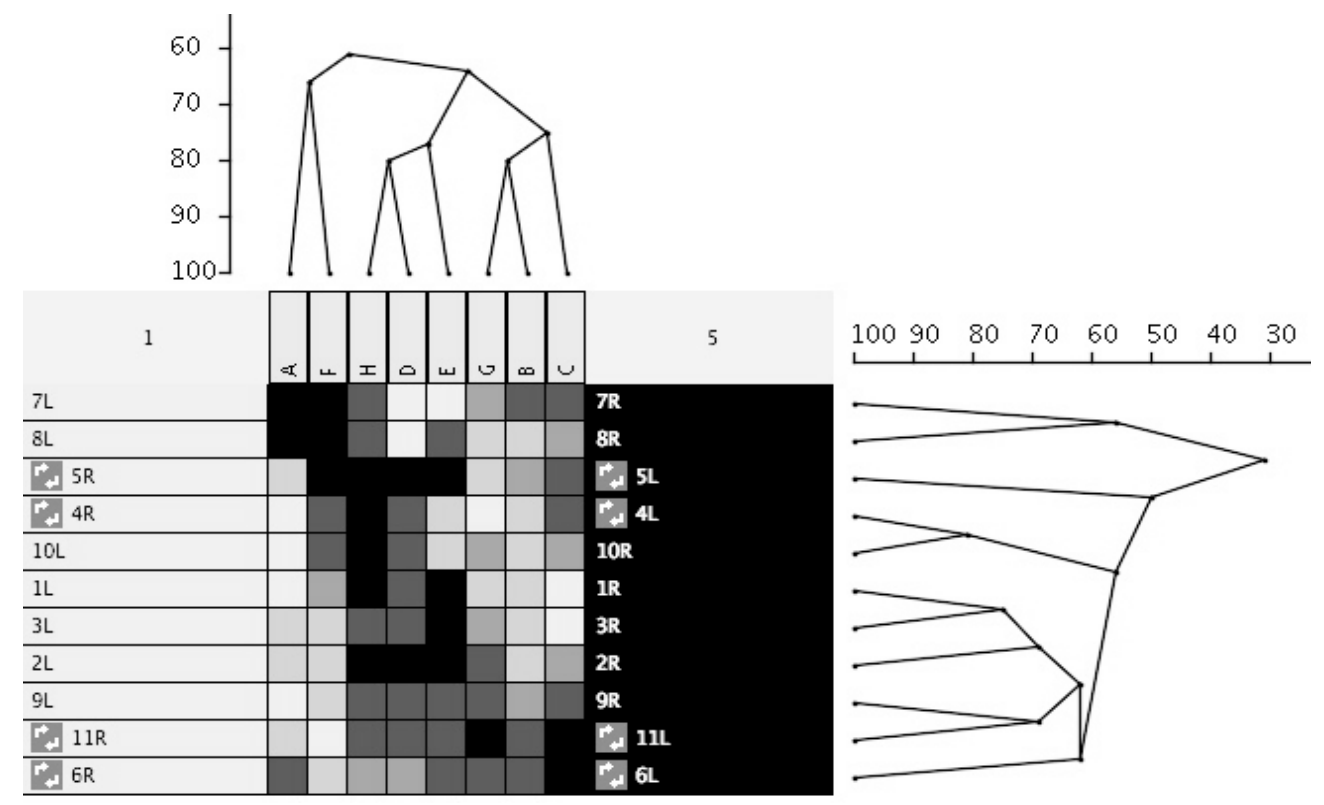

Figure 8 Repertory Grid: 8 elements by 11 constructs

The dendritic diagram at the top of the grid indicates nodal points or matching closeness factors of supervisors in three groups: (1) $A, F$ (Single supervisor and Ghost supervisor) at 67 pointing out at deficiencies supervisory situation. A second supervisory group (2) $H, D, E$ (Online interest groups such as CNBR, School academic board, School PhD students) at 80 indicating what would be a supportive environment (both, rational and emotional) for the PhD candidate. A third group (3) G,B,C (Two supervisors, One industry and one academic supervisor and Two academic and one industry) at 78 create an ideal supervisory mode, which could be suggested to be a most appropriate model for future student, supervisor, cosupervisor relationships.

\section{Conclusions}

This research concludes that to improve both thesis completion rates and the quality of research a model for student-supervisor interaction and satisfaction is essential. A technique to facilitate such a process in therefore proposed. The Repertory Grid Technique (RGT) can provide insights into the student-supervisor relationship by explicitly revealing views and perceptions. It can also provide stronger objectivity in the progress of the research and its assessment processes. As the result of utilising the RGT the research contends that this would contribute to improved communication in dealing with student-supervisor demands and expectations. It is also hypothesised that the level of anxiety in the supervisory process would be reduced if clear and transparent communication emerges.

This, in turn, can contribute to stronger objectivity in the progress of the research and its assessment processes. For example, Heath (2002) found that the differences between a student and a supervisor can be diminished by the frequency of meetings. This research argues that the 'quality' of such meetings is the most important factor.

This paper has put forward three main themes for consideration. The first describes the challenges in the current PhD research process and highlights the need to increase timely completions. Secondly, aspects relating to the research process are critically reviewed.

Aranda-Mena, G and Gameson, R (2012) 'An alignment model for the research higher degree supervision process using repertory grids - reflections on application in practice in built environment research', Australasian Journal of Construction Economics and Building, 12 (3) 66-81 
Finally, a model, initially conceptualised in 2004, has been extended and further developed using the RGT as a self administered reflective tool drawing upon a critical review of literature and the authors' experiences in supervising PhDs.

Although this research has been contextualised in the construction management domain the principles, and the RGT model, could be utilised for PhD's in other built environment related disciplines, such as economics and the social sciences, and in many other academic disciplines. The next logical stage of the research is to test this model by conducting an empirical, quantitative study.

\section{References}

Allport, G. W. (1935) Attitudes: a handbook of social psychology. Worcester, Mass: Clark University Press

Anderson, J. (1988) The supervisory process in speech language pathology and audiology, Boston: College Hill Press \& Little Brown

Aranda, G. \& Finch, E. (2003) 'Using repertory grids to measure changes in risk-taking behaviour', Journal of Construction Research - Special Issue in Construction Safety, 4 (1), 101-114

Aranda-Mena, G. \& Gameson, R. (2004) 'An alignment model for the research higher degree supervision process using repertory grids', Australian Universities Building Educators Association (AUBEA) Conference, Newcastle, Australia, July, 98-113

Baird, L. L. (1995) 'Helping graduate students: a graduate adviser's view', In Pruitt-Logan, A.S. \& Isaac, P.D. (eds.), Student services for the changing graduate student population; New Directions for Student Services, 72, San Francisco, CA: Jossey-Bass. 25-32

Barnes, B.J. and Austin, A.F. (2009) 'The role of doctoral advisors: A look at advising from the advisor's perspective', Innovation in Higher Education, 33 (5), 297-315

Black, T.R. (1993) Evaluating social science research: an introduction, London: Sage Publications

Boud, D. \& Lee, A. (2009) Changing practices is doctoral education, London: Taylor \& Francis

Bourne, L. (2005) Project relationship management and the stakeholder circle, Unpublished professional doctorate dissertation, RMIT University, Melbourne, Australia

Bradbury-Jones, C. (2007) 'Exploring research supervision through Peshkin's l's: the yellow brick road, Journal of Advanced Nursing, 60 (2), 220-228

Chynoweth, P. (2006) 'Professional doctorates in the built environment: how higher education is responding to the changing needs of industry and the professions', Built Environment Education Annual Conference (BEECON 2006): Where Industry and Practice, the Professions and Education Meet, London, September, 15

Commonwealth of Australia (2010, March 16) The excellence in research for Australia [ERA] initiative [online] http://www.arc.gov.au/era/

Cresswell, J.W. \& Miller, G.A. (1997) 'Research methodologies and the doctoral process', New Directions in Higher Education, 99, 33-46

Cullen, D. J., Pearson, M., Saha, L.J. \& Spear, R.H. (1994) Establishing effective PhD supervision, Department of Employment Education and Training [DEET], Australian Governmental Publishing Service

Dainty, A. (2008) 'Methodological pluralism in construction management research', In Knight, A. \& Ruddock, L. (eds.) Advanced Research Methods in the Built Environment, West Sussex: Wiley-Blackwell, 1-13 
Denicolo, P. M. \& Pope, M. (2001) Transformative professional practice: personal construct approaches to education and research, London: Whurr Publishers, London

Denicolo, P., Fuller, M. \& Berry, D. with Raven, C. (2010) A review of graduate schools in the UK, Staffordshire: UK Council for Graduate Education

Farrell, P. (2011) Writing a built environment dissertation: practical guidance and examples, West Sussex: Wiley-Blackwell

Federation of Australian University Staff Associations [FAUSA] (1979) Report on research in universities, Federation of Australian University Staff Associations, Melbourne, Australia

Fellows, R. \& Liu, A. (1997) Research methods for construction, London: Blackwell Science

Gatfield, T. (2005) 'An investigation into PhD supervisory management styles: development of a dynamic conceptual model and its managerial implications', Journal of Higher Education Policy and Management, 27 (3), 311-325

Grant, B. (2003) 'Mapping the pleasures and risks of supervision', Discourse; Studies In The Cultural Politics Of Education, 24 (2), 175-190

Griffith, A. \& Watson, P. (2008) 'Managing the thesis', In Knight, A. \& Ruddock, L. (eds.) Advanced Research Methods in the Built Environment, West Sussex: Wiley-Blackwell, 183192

Gurr, G. M. (2001) 'Negotiating the rackety bridge: a dynamic model for aligning supervisory style with research student development', Higher Education Research \& Development, 20 (1), 81-92

Haksever, A.M. \& Manisali, E. (2000) 'Assessing supervision requirements of PhD students: the case of construction management and engineering in the UK', European Journal of Engineering Education, 25 (1), 19-32

Harman, G. (2003) 'PhD student satisfaction with course experience and supervision in two Australian research-intensive universities', Prometheus, 21 (3), 317-333

Heath, T. (2002) 'A quantitative analysis of PhD students' views of supervision', Higher Education Research \& Development, 21 (1), 41-53

Higher Education Funding Council for England [HEFCE] (2005) PhD research degrees entry and completion, Issues Paper 2005/02, HEFCE

HEFCE (2011) PhD study - trends and profiles: 1996-97 to 2009-10, Issues Paper 2011/33, HEFCE

HEFCE (2011, March 15) Research Excellence Framework [REF], [online] http://www.hefce.ac.uk/research/ref/

HEFCE (2012) Rates of qualification from postgraduate research degrees, Issues Paper 2012/10, HEFCE

Hofstede, G. (1986) 'Cultural differences in teaching and learning', International Journal of Intercultural Relations, 10, 301-320

Holzer, D. (2009) Sense-making across collaborating disciplines in the early stages of architectural design, PhD (Embedded Practice), RMIT University, Melbourne, Australia.

Howard, K. \& Sharp, J.A. (1983) The management of a student research project. Aldershot: Gower Press

Hughes, W. (1994) 'The PhD in construction management', In Skitmore, M. \& Betts, M. (eds.) Proceedings of the $10^{\text {th }}$ annual conference of the Association of Researchers in Construction Management [ARCOM], Loughborough University, UK, 1, 76-87

Aranda-Mena, G and Gameson, R (2012) 'An alignment model for the research higher degree supervision process using repertory grids - reflections on application in practice in built environment research', Australasian Journal of Construction Economics and Building, 12 (3) 66-81 
Hughes, W. (1997) 'Construction management research: a field of application', Australasian Universities Building Education Association [AUBEA] - Third International Electronic Forum on Research and Education for Construction, 1, 6

Hunter, K. \& Kelly, J. (2008) 'Grounded theory', In Knight, A. \& Ruddock, L. (eds.) Advanced Research Methods in the Built Environment, West Sussex: Wiley-Blackwell, 86-98

Jankowicz, A.D. (1995) Business research projects ( $2^{\text {nd }}$ ed.), London: Chapman and Hall

Johnson, L., Lee, A. \& Green, B. (2000) 'The PhD and the autonomous self: gender, rationality and postgraduate pedagogy', Studies in Higher Education, 25 (2), 135-147

Kane, E. (1985) Doing your own research: how to do basic research in the social sciences and humanities, London: Marion Boyars

Kelly, G. (1955) The psychology of personal constructs, Vols. 1 and 2, Norton: New York

Knight, A. \& Ruddock, L. (eds.) (2008) Advanced research methods in the built environment, West Sussex: Wiley-Blackwell

Lawson, M. (2000) Being a PhD supervisor, Prepared by the Staff Development Training Unit, The University of Newcastle, Australia

Lee, A. (2007) 'Developing effective supervisors: Concepts of research supervision', South African Journal of Higher Education, 21 (4), 680-693

Lee, A. (2008) 'How are doctoral students supervised? Concepts of doctoral research supervision', Studies in Higher Education, 33 (3), 267-281

Leedy, P.D. (1985) Practical Research ( $3^{\text {rd }}$ ed.) New York: Macmillan

Marshall, C. \& Rossman, G.B. (1989) Designing qualitative research, California: Sage Publications

Martin, Y., Maclachlan, M. \& Karmel, T. (2001) Postgraduate completion rates, Department of Education, Training and Youth Affairs [DETYA], Canberra

Mostyn, B. (1985) 'The content analysis of qualitative research data: a dynamic approach', In Brenner, M., Brown, J. \& Canter, D. (eds.) The research interview: uses and approaches, London: Academic Press, 115-145

Neuman, W.L. (1997) Social research methods: Qualitative and quantitative approaches ( ${ }^{\text {rd }}$ ed.) Boston: Allyn and Bacon

Osgood, C. E. (1954) 'A blind analysis of a case of multiple personality using the semantic differential', Abnormal Psychology, 49, 579

Park, C. (2005) 'New variant PhD: The changing nature of the doctorate in the UK', Journal of Higher Education Policy and Management, 27 (2), 189-207

Perry, C. (1998) Thesis resource paper: a structured approach to presenting theses [online] http://www.uq.net.au/action research/art/cperry.html accessed 2011, March 19

Phillips, E.M. \& Pugh, D.S. (1987) How to get a PhD. Milton Keynes: Open University Press

Royal Melbourne Institute of Technology [RMIT] The doctor of project management (DPM) @ RMIT University [online] http://dhtw.tce.rmit.edu.au/pmgt/dpm.htm accessed 2011, March 22

RMIT (2007) Higher degrees by research: policies and procedures information booklet [online] http://mams.rmit.edu.au/6rp3m7h6fawnz.pdf accessed 2011, March 24

RMIT (2011a) Ethical issues and responsible practice policy - higher degrees by research [online] http://www.rmit.edu.au/browse;ID=qdvjsqchwsmf1 accessed 2011, March 23

RMIT (2011b) Requirements of research degrees policy - higher degrees by research [online] http://www.rmit.edu.au/browse;ID=04nydchcbbaf1 accessed 2011, March 24 
Runeson, G. \& Skitmore, M. (1999) Writing research reports: a practical guide for students of the built environment. Australia: Deakin University Press

Sinclair, M. (2004) The pedagogy of 'good' PhD supervision: a national cross-disciplinary investigation of PhD supervision, Australia: Commonwealth of Australia

Strauss, A. \& Corbin, J. (1990) Basics of qualitative research: grounded theory procedures and techniques. California: Sage Publications

The Quality Assurance Agency for Higher Education [QAA] (2001) The framework for higher education qualifications in England, Wales and Northern Ireland [online] http://www.qaa.ac.uk/academicinfrastructure/fheq/ewni/default.asp accessed 2011, March 25

Tinkler, P. \& Jackson, C. (2000) 'Examining the doctorate: institutional policy and the PhD examination process in Britain', Studies in Higher Education, 25 (2), 167-180

Truss, L. (2003) Eats, shoots and leaves: the zero tolerance approach to punctuation, London: Profile Books

University of Salford, Research Degrees - School of the Built Environment [online] http://www.sobe.salford.ac.uk/courses/research-degrees accessed 2011, March 15

University of Salford (2009) Professional doctorate [online]

http://www.professionaldoctorate.co.uk/ assessed 2011, March 18

University of Salford (2010a) Code of practice for the conduct of postgraduate research degree programmes [online]

http://www.governance.salford.ac.uk/cms/resources/uploads/File/AQA/PG Research Degre es Code of Practice.pdf accessed 2011, March 17

University of Salford (2010b) Governance and ethics [online] http://www.rgc.salford.ac.uk/page/forms accessed 2011, March 21

Vilkinas, T. (2002) The PhD process: the supervisor as manager, Education + Training, 44 (3), 129-137

Vitae (2011) Postgraduate researchers [online]

http://www.vitae.ac.uk/researchers/1218/Postgraduate-researchers.html accessed 2011, March 17

Walker, D.H.T. (2008) Collaborative academic/practitioner research in project management: theory and models, International Journal of Managing Projects in Business, 1 (1), 17-32

Whitelock, D., Faulkner, D. \& Miell, D. (2008) Promoting creativity in PhD supervision: tensions and dilemmas, Thinking Skills and Creativity, 3, 143-153

Wichmann-Hansen, G.M., Bach, L.W., Eika, B. \& Mulvany, M.J. (2012) 'Successful PhD supervision: a two-way process', In Castano, M.A.R.B. \& Guner-Akdogan, G. (eds.) Mentoring in Academia and Industry: Researching, Teaching, and Learning Triangle, Springer New York, 10 (2), 55-64 